\title{
In Focus
Spotlight on the May 13 Issue
}

\author{
Robert A. Gross, MD, PhD, FAAN \\ Editor-in-Chief, Neurology ${ }^{\circledR}$
}

Venous thromboembolism in amyotrophic lateral sclerosis: A prospective study :

Fifty patients with amyotrophic lateral sclerosis (ALS) were evaluated with bilateral venous duplex ultrasonography of the proximal leg veins at 6 and 12 months. Venous thromboembolism (VTE) was detected in 4 patients. Given these results, the potential benefits of routine VTE screening in high-risk patients with ALS with leg weakness should be explored.

See p. 1674; Editorial, p. 1668

\section{Progression types after antiangiogenic therapy are related to outcome in recurrent glioblastoma}

There is considerable debate regarding whether bevacizumab induces distinct types of progression in glioblastoma. Based on timely changes of MRI contrast enhancement and T2 signal, the authors identified 4 progression types with clear association to outcome. These may reflect resistance mechanisms to bevacizumab and may better guide postprogression therapies.

See p. 1684

From editorialists Wen \& Junck: "Ultimately, correlation of tumor genotype or baseline imaging characteristics with the different progression types may help identify patients who will not respond to bevacizumab and allow them to be treated with other agents." See p. 1670

\section{Plasma FGF23 and the risk of stroke: The Northern Manhattan Study (NOMAS)}

Emerging evidence implicates disordered phosphate homeostasis, marked by elevated levels of fibroblast growth factor 23 (FGF23), as a novel risk factor for cardiovascular disease. In the racially and ethnically diverse community-based Northern Manhattan Study, elevated plasma FGF23 levels measured at baseline were associated with increased risk of incident stroke, particularly intracerebral hemorrhage.

See p. 1700

\section{Time may not fully attenuate solvent-associated cognitive} deficits in highly exposed workers

Two thousand one hundred forty three persons underwent cognitive testing. Lifetime exposure to chlorinated solvents, petroleum solvents, and benzene was assessed using a job exposure matrix. Exposure to solvents during working life predicted postretirement impairment in multiple cognitive domains, with cognitive deficits persisting for decades.

See p. 1716

\section{Pituitary adenylate cyclase-activating polypeptide is reduced in Alzheimer disease}

The authors examined the brains of patients with confirmed late-onset Alzheimer disease and age-matched controls to investigate the expression of pituitary adenylate cyclaseactivating polypeptide messenger RNA and protein. Pituitary adenylate cyclase-activating polypeptide and its pathway may play an important role in Alzheimer disease pathogenesis, leading to novel therapeutic development.

See p. 1724

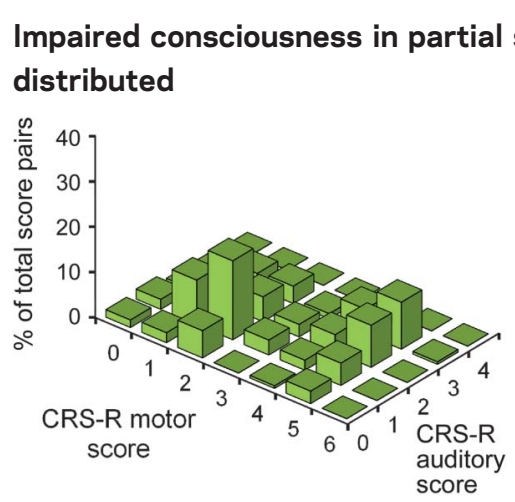

Deficits in partial seizures are commonly assumed to be of graded severity. Testing various cognitive functions during partial seizures instead revealed a bimodal distribution, with most episodes causing either a global encephalopathy-like state or spared cognition. The findings suggest that partial seizures can abruptly "switch" brain networks to impair consciousness.

See p. 1736

\section{SPECIAL ARTICLE}

Quality improvement in neurology: Distal symmetric polyneuropathy quality measures

Measuring quality of health care is a central part of health care plans. These quality measures focused on minimum metrics for patients with a diagnosis of distal symmetric polyneuropathy (DSP). In identifying 6 quality measures, this article defines basic yet critical DSP measures to improve health outcomes.

See p. 1745

NB: "Spontaneous intracranial hypotension with camptocormia," see p. 1751. To check out other Video Neurolmages, point your browser to Neurology.org. 


\section{Neurology}

Spotlight on the May 13 Issue

Robert A. Gross

Neurology 2014;82;1667

DOI 10.1212/WNL.0000000000000443

\section{This information is current as of May 12, 2014}

\section{Updated Information \&} Services

Permissions \& Licensing

Reprints including high resolution figures, can be found at: http://n.neurology.org/content/82/19/1667.full

Information about reproducing this article in parts (figures,tables) or in its entirety can be found online at:

http://www.neurology.org/about/about_the_journal\#permissions

Information about ordering reprints can be found online:

http://n.neurology.org/subscribers/advertise

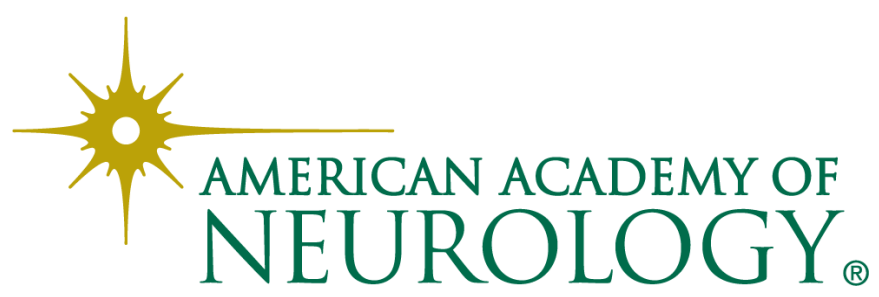

